\title{
Anesthetic experience of an adult patient with an unrecognized tracheal bronchus -A case report-
}

\author{
Yong Seon Choi ${ }^{1,2}$, Young Lan $\mathrm{Kwak}^{1,2}$, Hong Gyu Choi ${ }^{1}$, Se Young Oh${ }^{1}$, and Jong Wha Lee ${ }^{1,2}$ \\ ${ }^{1}$ Department of Anesthesiology and Pain Medicine, ${ }^{2}$ Anesthesia and Pain Research Institute, College of Medicine, Yonsei University, \\ Seoul, Korea
}

We present a case of problematic tracheal intubation in an adult patient with an unrecognized tracheal bronchus. Immediately after tracheal intubation and position change to prone, bilateral breath sounds were almost absent, and there was a diminished tidal volume. In order to resolve the ventilatory difficulty, the wire-reinforced tube was replaced with a conventional tube, and proper positioning of the tube was completed under fiberoptic guidance. A tracheal bronchus (originating about $1.2 \mathrm{~cm}$ above the carina, and supplying the right upper lobe) was found on the postoperative chest CT. In the presence of tracheal bronchus, tracheal intubation may cause pulmonary complications. Anesthesiologists should keep in mind the anesthetic implications of tracheal bronchus, and must be familiar with the use of fiberoptic bronchoscopy for proper positioning of endotracheal tube. (Korean J Anesthesiol 2010; 59: S13-S16)

Key Words: Endotracheal intubation, Tracheal bronchus.

Tracheal bronchus (TB), arising from the lateral wall of the trachea above the carina, and usually supplying the right upper lobe, is the most common congenital abnormality of the tracheobronchial tree [1]. TB can present challenges for the anesthesiologists, and have serious clinical implications for anesthetic management. It has been reported that TB occurs approximately in $0.1-3 \%$ of the population, and it is usually asymptomatic $[1,2]$. Several investigators have described events in which an endotracheal tube (ETT) had obstructed, or accidentally migrated into a $\mathrm{TB}$, resulting in right upper lobe atelectasis or inadequate ventilation of the remaining lung fields, both of which ultimately led to hypoxemia [3-7]. We present a case of an adult patient with known tracheal deviation and an unrecognized tracheal bronchus that led to inadequate ventilation of the lungs immediately after tracheal intubation and position change to prone.

Received: April 5, 2010. Revised: April 20, 2010. Accepted: April 30, 2010.

Corresponding author: Jong Wha Lee, M.D., Department of Anesthesiology and Pain Medicine, College of Medicine, Yonsei University, 134, Sinchon-dong, Seodaemun-gu, Seoul 120-752, Korea. Tel: 82-2-2228-8500, Fax: 82-2-364-2951, E-mail: jhanes@yuhs.ac

(c) This is an open-access article distributed under the terms of the Creative Commons Attribution Non-Commercial License (http:// creativecommons.org/licenses/by-nc/3.0/), which permits unrestricted non-commercial use, distribution, and reproduction in any medium, provided the original work is properly cited. 


\section{Case Report}

A 44-year-old male, weighing $79 \mathrm{~kg}$ with a height of $176 \mathrm{~cm}$, and presenting with ossification of the posterior longitudinal ligament, was scheduled for multi-level cervical laminectomy using the posterior approach. Aside from pulmonary tuberculosis completely treated 20 years ago, his past history was unremarkable. The patient was newly diagnosed with hypertension and diabetes mellitus after admission, and was placed on anti-hypertensive medication thereafter. A preoperative chest radiograph revealed apical thickening and volume loss in the right upper lobe, and blunting of the right cardiopulmonary angle (Fig. 1). Pulmonary function test did not reveal major obstructive or restrictive pulmonary disease, and echocardiography showed normal sized cardiac chambers and normal valvular function with a left ventricular ejection fraction of $59 \%$.

Upon arrival at the operating theater, standard monitoring devices, including ECG lead II, pulse oximetry and oscillometric non-invasive blood pressure, were applied. Before the induction of anesthesia, glycopyrrolate $0.02 \mathrm{mg}$ was given intravenously. Anesthesia was induced with remifentanil $0.5 \mu \mathrm{g} / \mathrm{kg}$ bolus, followed by $0.1 \mu \mathrm{g} / \mathrm{kg} / \mathrm{min}$ infusion, and propofol $1.5 \mathrm{mg} / \mathrm{kg}$. Tracheal intubation with a $7.0 \mathrm{~mm}$ (I.D.) wire-reinforced tube (Mallinckrodt Medical, Athlone, Ireland) using a light wand was facilitated with rocuronium $0.6 \mathrm{mg} / \mathrm{kg}$, and the insertion depth was $23 \mathrm{~cm}$ at the upper incisors. When both lung fields were auscultated after intubation, only weak, high-pitched sounds were heard with high resistance felt upon manual ventilation. The ventilator, set for a tidal volume $\left(\mathrm{V}_{\mathrm{T}}\right)$ of $650 \mathrm{ml}$,

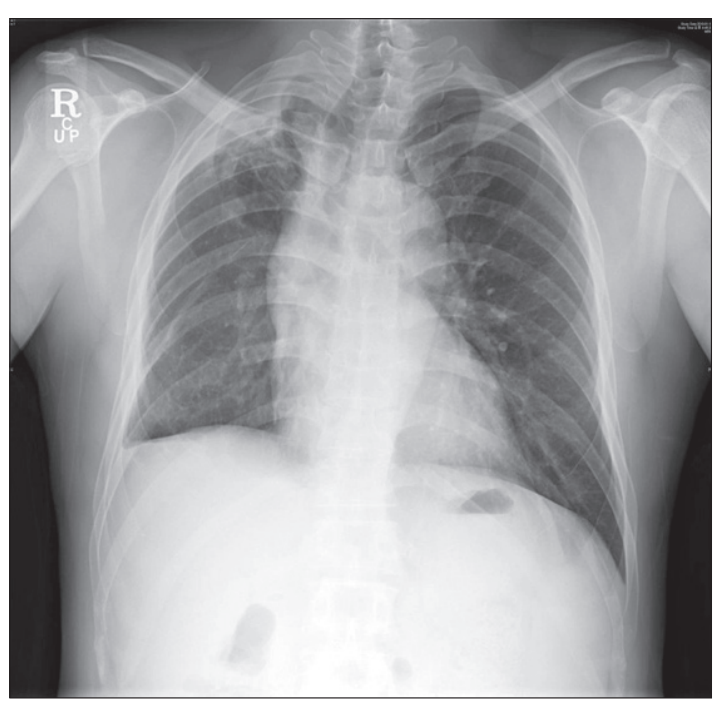

Fig. 1. Preoperative chest radiograph shows apical thickening and volume loss in the right upper lobe, blunting of the right cardiopulmonary angle and rightward tracheal deviation. was able to deliver $\mathrm{V}_{\mathrm{T}}$ of only $180-220 \mathrm{ml}$ with peak inspiratory pressure (PIP) of $45 \mathrm{cmH}_{2} \mathrm{O}$. Bronchospasm was suspected, so the inspired concentration of sevoflurane was raised to $6 \mathrm{vol} \%$, dexamethasone $10 \mathrm{mg}$ was injected intravenously, and $100 \%$ oxygen was supplied. Although the arterial oxygen saturation $\left(\mathrm{SaO}_{2}\right)$ was maintained at $98-100 \%$, the elevated PIP did not decrease and $\mathrm{V}_{\mathrm{T}}$ was continuously reduced. An arterial blood gas (ABG) showed $\mathrm{pH}$ of 7.309, $\mathrm{PaCO}_{2}$ of $55.8 \mathrm{mmHg}$ and $\mathrm{PaO}_{2}$ of $470.9 \mathrm{mmHg}$, representing respiratory acidosis. A chest radiograph, taken to rule out bronchial intubation or pneumothorax, showed only the tracheal deviation to the right side and about $2 \mathrm{~cm}$ distance between the tip of the ETT and the carina (Fig. 2).

Fiberoptic bronchoscopy was performed, to rule out a thickened mucous plug. Bronchoscopy showed no mucous plugging, however, the beveled end of the wire-reinforced tube was almost completely obstructed by the mucosal wall. The proper position of the ETT could not be verified because of the tracheal deviation. Therefore, the ETT was gradually withdrawn to 21 $\mathrm{cm}$ at the upper incisor, and then rotated until the lumen of the ETT became patent under the fiberoptic guidance. The PIP immediately decreased to $22 \mathrm{cmH}_{2} \mathrm{O}$ with a $\mathrm{V}_{\mathrm{T}}$ of approximately $8 \mathrm{ml} / \mathrm{kg}$, a respiratory rate of 10 breaths $/ \mathrm{min}$ and a positive end-expiratory pressure of $5 \mathrm{cmH}_{2} \mathrm{O}$. After confirming that equal breath sounds were auscultated bilaterally, and $\mathrm{SaO}_{2}$ was maintained at $99-100 \%$ with $40 \%$ oxygen in air, the patient was turned to the prone position onto the chest rolls. During pinning of the head, the ventilator was again able to deliver a $\mathrm{V}_{\mathrm{T}}$ of only $180 \mathrm{ml}$ with the PIP increased to $45 \mathrm{cmH}_{2} \mathrm{O}$. Additionally, bilateral breath sounds were again diminished.

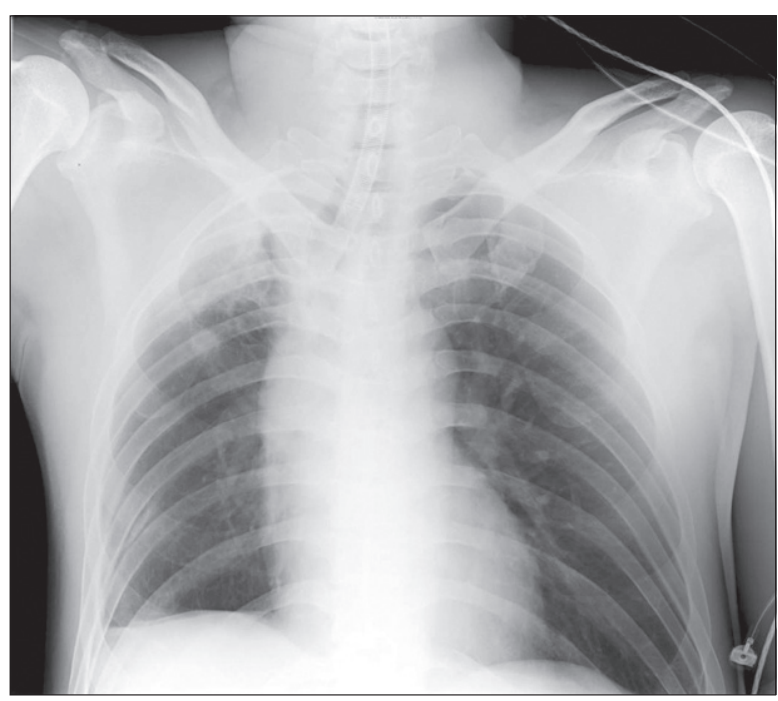

Fig. 2. Intraoperative chest radiograph shows the curvature of the wire-reinforced tube facing rightward, instead of upward, but does not show the presence of bronchial intubation or pneumothorax. 


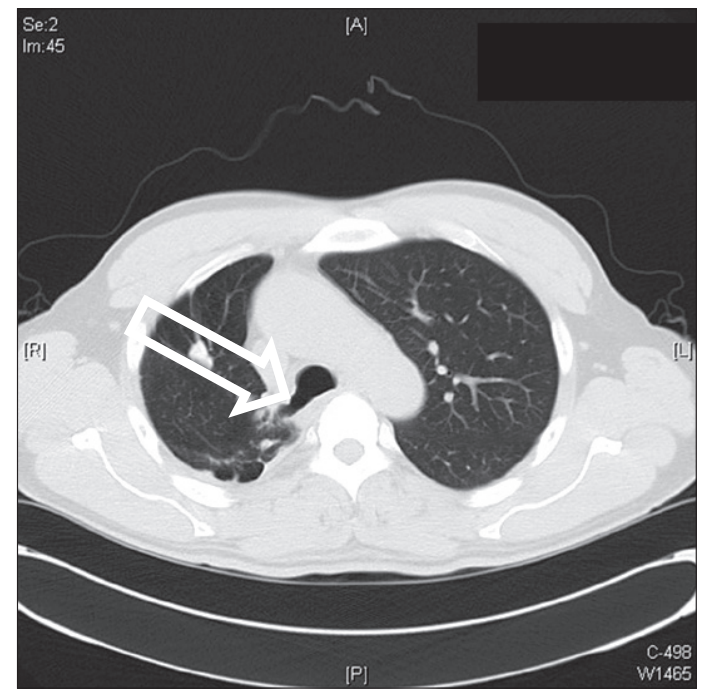

Fig. 3. Postoperative chest computerized tomography scan shows a tracheal bronchus supplying the right upper lobe and originating from the right lateral tracheal wall $1.2 \mathrm{~cm}$ above the carina (designated by the white arrow).

When the patient was returned to the supine position, the PIP immediately decreased to $22 \mathrm{cmH}_{2} \mathrm{O}$ with an adequate $\mathrm{V}_{\mathrm{T}}$. As the nearly complete obstruction of the beveled tip of the wirereinforced tube was considered to be the primary cause, the wire-reinforced tube was replaced with a polyvinyl chloride (PVC) tube with a Murphy-eye side hole (Mallinckrodt Medical, Athlone, Ireland).

Thereafter, the patient was placed prone onto the Wilson frame, and the PIP was stably maintained with adequate ventilation. There was no apparent hypoxemia during the surgical procedures. At the end of the surgery, an ABG showed $\mathrm{pH}$ of $7.388, \mathrm{PaCO}_{2}$ of $35.0 \mathrm{mmHg}$, and $\mathrm{PaO}_{2}$ of $257.9 \mathrm{mmHg}$. The patient was extubated and then transferred to the general ward. Chest computerized tomography, taken for postoperative evaluation, revealed a tracheal bronchus supplying the right upper lobe and originating from the right lateral tracheal wall $1.2 \mathrm{~cm}$ above the carina (Fig. 3). The patient was discharged on the seventh postoperative day without any pulmonary complications.

\section{Discussion}

If, during general endotracheal anesthesia, there is a sudden surge in PIP with a falling $\mathrm{V}_{\mathrm{T}}$, mechanical obstruction of the anesthesia circuit, including the ETT, should be suspected. However, when one cannot find any mechanical defect in the anesthesia circuit, obstructive airway conditions, such as laryngospasm or bronchospasm, asthmatic attack, or pneumothorax, should be ruled out. In this case, the anesthesia circuit was inspected above all, including endotracheal suction to confirm the patency of the ETT, and no definite obstruction was found. As a result, obstructive airway conditions were sought as a possible cause, and thus deepening the level of anesthesia was done. Even though an adequate level of anesthesia had been obtained, the elevated PIP did not improve. Consequently, fiberoptic bronchoscopy was performed to rule out a possible mucous obstruction. During bronchoscopy, the beveled end of the wire-reinforced ETT was found to be nearly obstructed against the mucosal wall, and then the ETT was withdrawn and rotated until the opening was clear and patent. Soon thereafter, all the ventilatory parameters recovered.

A preoperative chest radiograph revealed a rightward tracheal deviation, then considered as a consequence of previous pulmonary tuberculosis, but no other tracheobronchial abnormalities. Furthermore, during intraoperative fiberoptic bronchoscopy, the obstruction of the wire-reinforced ETT was evident, but the TB was not visualized. It was not only attributed to the tracheal deviation which made it difficult to navigate the bronchoscope, but also to "no doubt" of any tracheobronchial abnormality. The clinical implications of the TB mainly manifested with endotracheal intubation, and the most effective method to mitigate those clinical implications is the recognition of the TB beforehand [3,8-10].

Case reports of tracheal bronchus during general anesthesia have almost always been related to ventilatory difficulty, which ultimately led to hypoxemia due to an obstructed accessory or ectopic bronchus to the right upper lobe or its subsegments [37]. Those reports mostly addressed the use of a conventional PVC ETT or a double-lumen endobronchial tube. In this case, however, a wire-reinforced tube was utilized. When manufactured, the ETT is molded at a certain angle, giving the ETT a curvature. During tracheal intubation, anesthesiologists usually insert the ETT with its curvature facing upward. But, in this case, as shown in the chest radiograph taken intraoperatively, the natural curvature of the wire-reinforced tube was facing rightward. This may have facilitated the beveled end of the ETT migrating into the tracheal bronchus, subsequently causing it to be blocked against the mucosal wall. The more soft and flexible nature of a wire-reinforced ETT, compared to a conventional PVC ETT, may have also facilitated its rotation in the rightward deviated trachea. And the ventilatory problems may have also been aggravated by the absence of Murphy-eye side hall, which is designed to allow ventilation even in the event of obstruction $[11,12]$. The reappearance of ventilatory difficulty with position change to prone was probably attributed to migration or displacement of the wire-reinforced ETT, caused by flexion and/or rotation of the neck during pin fixation [13]. Reportedly, flexion of the neck can move the tip of an ETT downward and closer to the carina in adult and pediatric patients [14]. The replacement of 
the wire-reinforced ETT with a conventional PVC ETT, using bronchoscope-aided proper positioning, relieved the ventilatory difficulty thereafter even with the patient in the prone position, as a conventional ETT is less soft and flexible, and has Murphyeye side hall.

The management issues out of this case are as follows: First, all the clinical features, such as the sudden increase in PIP, and the diminished bilateral breath sounds and $V_{T}$, were misinterpreted as being due to an obstructive airway condition. This could be due to a variety of specific clinical circumstances, including volume loss and subsequently reduced breath sound in the right upper lobe with post-tuberculosis cicatricial change, or probably "partial" obstruction of the beveled end of the ETT, as $\mathrm{SaO}_{2}$ was maintained with a reduced $\mathrm{V}_{\text {T. }}$. But it is primarily attributable to the complete lack of suspicion of a tracheobronchial abnormality. Second, it is of great importance to use the fiberoptic bronchoscopy quickly. With fiberoptic bronchoscopy, anesthesiologists can visualize the obstructed ETT and properly position the tip of the ETT. The combination of these actions could lead to immediate resolution of the ventilatory difficulty, even though the TB was not found then.

In conclusion, anesthesiologists should keep in mind the anesthetic implications of a tracheobronchial abnormality, and also must be familiar with the use of fiberoptic bronchoscopy to allow for confirmation of this specific anatomic variant and for prompt positioning of an ETT.

\section{References}

1. McLaughlin FJ, Strieder DJ, Harris GB, Vawter GP, Eraklis AJ.
Tracheal bronchus: association with respiratory morbidity in childhood. J Pediatr 1985; 106: 751-5.

2. Siegel MJ, Shackelford GD, Francis RS, McAlister WH. Tracheal bronchus. Radiology 1979; 130: 353-5.

3. Ikeno S, Mitsuhata H, Saito K, Hirabayashi Y, Akazawa S, Kasuda H, et al. Airway management for patients with a tracheal bronchus. Br J Anaesth 1996; 76: 573-5.

4. Sripada R, Keys K, Eichholz KM. Inability to ventilate the lungs of a patient with tracheal anomaly and in prone position. J Clin Anesth 2008; 20: 386-8.

5. Brodsky JB, Mark JB. Bilateral upper lobe obstruction from a single double-lumen tube. Anesthesiology 1991; 74: 1163-4.

6. Pribble CG, Dean JM. An unusual cause of intraoperative hypoxemia. J Clin Anesth 1994; 6: 247-9.

7. Venkateswarlu T, Turner CJ, Carter JD, Morrow DH. The tracheal bronchus: an unusual airway problem. Anesth Analg 1976; 55: 746-7.

8. O'Sullivan BP, Frassica JJ, Rayder SM. Tracheal bronchus: a cause of prolonged atelectasis in intubated children. Chest 1998; 113: 53740.

9. Setty SP, Michaels AJ. Tracheal bronchus: case presentation, literature review, and discussion. J Trauma 2000; 49: 943-5.

10. Cha JW, Kwak SH, Kim SJ, Kim CM, Jeong ST, Bae HB, et al. Anesthetic experience of patients with a congenital tracheal bronchus - a report of two cases. Korean J Anesthesiol 2006; 51: 63840.

11. Murphy FJ. Two improved intratracheal catheters. Anesth Analg 1941; 20: 102-5.

12. Tamakawa S. Every endotracheal tube needs a Murphy eye! Can J Anaesth 1999; 46: 998-9.

13. Wong DT, Kumar A. Case report: endotracheal tube malposition in a patient with a tracheal bronchus. Can J Anaesth 2006; 53: 810-3.

14. Kim JT, Kim HJ, Ahn W, Kim HS, Bahk JH, Lee SC, et al. Head rotation, flexion, and extension alter endotracheal tube position in adults and children. Can J Anaesth 2009; 56: 751-6. 